Ambientes naturales y ambientes virtuales de aprendizaje

Josefina Quintero Corzo Fabio Ignacio Munévar Quintero Diana Yurany Alvarez Márquez

- Teorías de la corporeidad y pensamiento científico: derivación de disponibilidades en la comprensión de sistemas físicos

Geral Eduardo Máteus Ferro José Otero

- La enseñanza de la nanociencia: un acercamiento mediante imágenes María del Carmen Sánchez-Mora

¿De qué ciencia hablan nuestros materiales de divulgación? 


\section{Resumen}

Este artículo nace del trabajo de investigación "Diseño, aplicación y validación de un ambiente informático adaptativo para el aprendizaje”, desarrollado entre la Universidad de Caldas y la Universidad Nacional de Colombia, Sede Manizales. Revela el proceso pedagógico y tecnológico para elaborar materiales didácticos multimedia, accedidos desde una plataforma virtual, después de identificar los estilos de aprendizaje visual, auditivo, kinético y lecto-escritor. Más allá de la temática curricular desarrollada para diferenciar los conceptos de medio ambiente social y medio ambiente natural, en un grupo de escolares, los resultados y conclusiones dejan aportes significativos en torno a la interactividad que se genera en un sistema de aprendizaje adaptativo llamado "Savmoodle" y se establecen las relaciones entre escenarios pedagógicos naturales y virtuales.

\section{Palabras clave}

Ambiente de aprendizaje, ambiente natural, ambiente virtual, sistema adaptativo, plataforma de aprendizaje, estilos de aprendizaje.

\section{Abstract}

This article reports a study entitled "Design, implementation and validation of a computer adaptive learning environment". The study was developed at Universidad de Caldas and Universidad Nacional in Manizales, Colombia, South America. A process for developing technological multimedia learning materials accessed on a virtual platform is presented. Variables such as visual, auditory, kinetic and reader-writer learning styles were considered. Findings indicate that this curriculum development allowed a group of elementary students to differentiate natural and social environments. In addition, the main findings and conclusions make significant contributions to the interactivity that is generated in the adaptive learning system called "Savmoodle". Relationships between natural and virtual educational settings are also established.

\section{Key words}

Learning environment, natural environment, virtual environment, adaptive system, learning platform, learning styles. 


\title{
Ambientes naturales y ambientes virtuales de aprendizaje ${ }^{1}$
}

\author{
Josefina Quintero Corzo² \\ Fabio Ignacio Munévar Quintero³ \\ Diana Yurany Álvarez Márquez ${ }^{4}$
}

Desde su génesis, cuando se creó la escuela, ya existían herramientas creadas por el hombre para transformar la naturaleza; hoy, se siguen inventando diferentes recursos, para comunicar el conocimiento, que son utilizados por el maestro para favorecer la relación pedagógica con sus alumnos. Si hace siglos, los precursores de la pedagogía activa impartían enseñanza mediante el libro impreso, y el libro abierto de la naturaleza, hoy, sus ideas siguen vigentes en los ambientes virtuales adaptados a los estilos de aprendizaje, en el fomento del aprendizaje colaborativo, en el incremento de la interactividad y la interdisciplinariedad.

Actualmente, por medio de foros de discusión, correo electrónico, listas de mensajería, pizarras electrónicas, blogs, tags, plataformas moodle, sitios web, entre otros, la comunidad académica cuenta con nuevos entornos geográficos y ciberespaciales para acceder al conocimiento. Es posible aprender desde cualquier lugar del mundo, conectados a redes que transportan grandes volúmenes de información a un mayor número de personas mediante códigos digitales en menor tiempo, esfuerzo y, posiblemente, a menor costo.

\footnotetext{
${ }^{1}$ Texto recibido el 18 de marzo, evaluado el 23 de junio y el 24 de junio y arbitrado el 30 de junio de 2009.

2 Doctora en Educación de la Universidad de Antioquia. Profesora Titular Universidad de Caldas, Directora del Grupo Inacmes, Categoría A de Colciencias. josefina.quintero@ucaldas.edu.co

${ }^{3}$ Estudiante tesista de la Maestría en Educación de la Universidad de Caldas. Joven Investigador Colciencias. Coordinador del Semillero Edumática de la Universidad de Caldas. Administrador de Sistemas Informáticos de la Universidad Nacional de Colombia, Sede Manizales. fimunevar@gmail.com

${ }^{4}$ Estudiante Maestría en Educación de la Universidad de Caldas. Joven Investigadora Colciencias. Licenciada en Biología y Química de la Universidad de Caldas. yura827@gmail.com
} 
El proyecto del cual se deriva este artículo, surgió de los desarrollos progresivos de dos grupos, escalafonados por Colciencias, que comparten saberes en cada uno de sus campos de acción y producen materiales didácticos impresos, multimediales y virtuales sustentados en sus respectivas líneas de investigación. El grupo Innovacción Educativa, de la Universidad de Caldas, junto con estudiantes tesistas de la Maestría en Educación y el Semillero Edumática, se encargó de diseñar el modelo curricular y pedagógico, los guiones didácticos y los componentes multimedia. El grupo Ambientes Inteligentes Adaptativos, Gaia, de la Universidad Nacional de Colombia, Sede Manizales, aportó elementos de los ambientes inteligentes, los procesos de adaptación de cursos y el montaje de la plataforma.

En relación con las teorías modernas del aprendizaje activo, los ambientes virtuales se están utilizando cada vez con mayores impactos. Es importante reconocer que las diferencias sociales, culturales y psicológicas, de cada estudiante, determinan formas particulares de aprender, contextualizar y organizar la información que va adquiriendo. El estudiante no almacena pasivamente datos aislados desprovistos de significado, por el contrario, va adaptando y utilizando sus propios métodos y estrategias, las cuales son diferentes de acuerdo con sus intereses y percepciones del mundo. De ahí el propósito de este artículo para mostrar cómo se creó un ambiente adaptado a los estilos de aprendizaje visual, auditivo, lector-escritor y kinético, detectados en un grupo de escolares de una institución pública.

Otro antecedente importante es la política de formación y relevo generacional, mediante semilleros adscritos a los grupos de investigación, que permitió trabajar interdisciplinariamente con estudiantes de diseño visual, programadores de sistemas, licenciados en educación ambiental, biología y química y otros expertos en calidad de auxiliares de investigación. Asimismo, de los resultados de éste se derivó un nuevo proyecto titulado "La relación pedagógica en ambientes virtuales de aprendizajes urbanos y rurales”, para dar continuidad a las líneas de investigación del grupo.

\section{El problema y su contexto}

El proceso evolutivo de fabricación y uso de herramientas, cada vez más complejo y sofisticado, ha generado mejores opciones de comunicación e interacción entre las generaciones. El hacha y la piedra marcaron huellas imperecederas para la memoria histórica; con el papiro, el papel y la pluma se logró conservar y difundir el conocimiento producido por el hombre en relación con su mundo.

En todos los sistemas educativos existentes en el transcurso de la historia, uno de los principales recursos de mayor utilización, para aprender y enseñar, ha sido el material impreso. Con la llegada de las Tecnologías de la Información y Comunicación se ha dado un vuelco radical, del texto plano hacia hipertextos didácticos interactivos multimediales e hipermediales. Si con el libro impreso se masificó el 
conocimiento, con Internet, el acceso a la información y al conocimiento se ha vuelto global e instantáneo. También han proliferado grandes volúmenes de otros materiales interactivos en formatos electrónicos muy apetecidos por niños, jóvenes y adultos, con repercusiones sorprendentes en los ambientes pedagógicos.

La cultura electrónica ha incidido en las formas de pensar, enseñar, aprender y educar; ha modificado las habilidades, destrezas, competencias y estilos de vida de las nuevas generaciones que, a su vez, reclaman nuevas formas de saber hacer. Según Negroponte (1995), cada generación es más digital que la anterior. Este rasgo generacional cuestiona la educación tradicional y lleva a las instituciones educativas a modernizar las mediaciones pedagógicas. De acuerdo con Gardner (2005, p. 12), "la indudable hegemonía de la ciencia y de la tecnología plantea nuevos retos al mundo de la educación. Los jóvenes deben aprender a pensar de una manera científica si quieren entender el mundo moderno y participar en él".

Los ambientes virtuales de aprendizaje abren nuevas posibilidades para utilizar recursos multimedia como imágenes, texto, sonido y animación, porque implican un factor motivacional en el proceso de representación de símbolos, conceptos y temáticas. Resultados de estudios e investigaciones son los mostrados por Galvis (1997), Gallego (2004), Gardner (2005), González, Duque y Ovalle (2008), Negroponte (1995), Rogers y Freiberg (1986), Silvio (2000), entre otros, que permiten evidenciar la pertinencia y utilidad de plataformas tecnológicas para trabajar la motivación, la creatividad, el desarrollo de la inteligencia, el aprendizaje autónomo, los estilos de aprendizaje, el desarrollo del lenguaje y del pensamiento.

Comprender el poder de adaptabilidad de los materiales interactivos permite identificar cómo aprenden las generaciones jóvenes en estos ambientes. En este contexto surge el problema de investigación, sobre el diseño y la aplicación de un sistema informático adaptativo, para escolares de diferentes estilos de aprendizaje, en el área de educación ambiental.

\section{Pregunta de investigación}

¿Cuál es el proceso de construcción, aplicación y validación, de un ambiente adaptativo virtual para el aprendizaje de estudiantes, teniendo en cuenta los estilos de aprendizaje en el área de educación ambiental?

\section{Objetivos}

- Crear un ambiente informático adaptativo para el aprendizaje, orientado a estudiantes de educación básica, en el área de educación ambiental.

- Determinar la estrategia de adaptación en cuanto a características de los estudiantes, materiales interactivos, actividades y logros de aprendizaje. 
- Caracterizar la plataforma que apoye el ambiente informático adaptativo para diferentes estilos de aprendizaje, orientado a estudiantes de educación básica en el área de educación ambiental.

- Evaluar el grado de adaptación que ofrece la herramienta.

\section{De los ambientes naturales a los ambientes virtuales}

En correspondencia con las preguntas de investigación, los objetivos y los procesos aplicados en la creación del ambiente adaptado a los estilos de aprendizaje, este apartado desarrolla cuatro subapartados en los que se muestra el tránsito o la evolución de los ambientes naturales, que caracterizaron los métodos escolares de la pedagogía activa de hace varios siglos, y su continuidad en los modernos ambientes virtuales, como consecuencia de las nuevas Tecnologías de la Información y la Comunicación.

\section{Transformación de la naturaleza}

La naturaleza estuvo presente, aún desde la concepción mítica del mundo, en las preocupaciones del hombre. El hombre, en el tránsito del mitos al logos, fue capaz de explicar, con sus razonamientos, el origen de la realidad y las leyes que la rigen. Al desmitificarla, la naturaleza se vuelve objeto de conocimiento; el mundo se concibe mediante racionalidad y está sujeto a intervención, control y dominio. Los rasgos, que definen la naturaleza humana, pueden expresarse con ayuda de la capacidad del hombre para fabricar y usar las herramientas que necesita para adaptarse al medio en el que vive. El hombre, con la ayuda de herramientas, se autorrealiza, se autodetermina, se comunica, aprende, tiene conciencia de sí, transforma su mundo y construye una segunda naturaleza, o sea, la cultura.

En cada etapa de desarrollo de las diferentes culturas existe una tecnología dominante que condiciona la manera de aprender y hacer las cosas. Las etapas de fabricación de las herramientas, la técnica y la tecnología son paralelas al desarrollo científico, cultural y humano. Como indicadoras de autorrealización, han estado presentes en la caza, la vivienda, la agricultura, la guerra, en el arte y, por supuesto, se convierten en motor de cambio educativo, económico y de bienestar social. Gallego-Badillo (1998, p. 21) afirma que "incluso el lenguaje o, mejor, los diferentes lenguajes en la óptica del dominio cultural y social del mundo son considerados también como parte de su equipo instrumental, elaborado y perfeccionado a lo largo de la historia".

La evolución del homo habilis, el homo erectus y el homo sapiens, indica un alto grado de imaginación y poder creador en el diseño original de herramientas y en su esfuerzo por adaptarse y transformar la naturaleza. "Lo cierto es que el acto de codificar y de decodificar los fenómenos psíquicos, sociales y naturales es, de por sí, un ordenamiento de la realidad sin el cual su aprehensión humana resultaría imposible" (Gallego-Badillo, 1998, p. 21). 
Desde las pinturas rupestres y las esculturas prehistóricas, la construcción y el uso de herramientas, identificó la interacción del hombre con su mundo. Del sistema convencional de símbolos registrados en las cavernas a partir de animales y objetos del entorno, se derivan interpretaciones acerca del poder mágico, religioso, estético y comunicativo. Los códigos lingüísticos orales, mímicos y gráficos se inspiraron en la observación de la naturaleza y evolucionaron en los sistemas de escritura, acompañados de imágenes, símbolos visuales y audiovisuales, fijos o móviles, estáticos o cinéticos. Hoy, la cultura electrónica, cibernética y multimedial emergente, utiliza nuevas herramientas que posibilitan la transformación de los medios, los espacios y los ambientes de interacción con la primera naturaleza (el mundo real) y con la segunda naturaleza (la cultura).

\section{La naturaleza como contenido curricular y como recurso didáctico}

El estudio y la protección de la naturaleza, junto con el lenguaje y las matemáticas, han sido temas fundamentales, de los planes curriculares, en todos los sistemas del mundo. Pero, más allá de un listado de contenidos enseñables, los precursores de la escuela activa siempre eligieron la naturaleza como escenario para los procesos de aprendizaje en todas las áreas del saber y como modelo imitable en la formación integral o perfectible del hombre. Para la enseñanza del número, el arte, la música, el cálculo y el dibujo, así como en el desarrollo del razonamiento, el pensamiento y el lenguaje, la naturaleza fue el mejor recurso didáctico adoptado en la escuelas de Comenio, Rousseau y Pestalozzi, en los siglos XVI y XVIII.

Estos memorables pedagogos influyeron en otros educadores como Herbart (1776-1841), Froëbel (1782-1852), Decroly (1871-1932), Freinet (1896-1966), Montessori (1870-1952), Dewey (1859-1845) y muchos más, que prefirieron enseñar en la realidad antes que en los libros, romper los muros de la escuela, llevar el niño al campo, aprender al aire libre, respirar en el bosque, estimular los sentidos, trabajar jugando, observar y experimentar, ensayar en el taller, realizar caminatas, recolectar materiales, cultivar la tierra, incorporar proyectos comunitarios al currículo, pues la naturaleza es un libro vivo. En fin, se debe aprender en la escuela como se aprende en la vida real. Pestalozzi (1996) decía:

Tenemos que examinar de una manera precisa y minuciosa, en este respecto, la naturaleza y los medios de educación elemental, en tanto son medios del arte humano, con relación al proceso de la naturaleza en el desenvolvimiento de nuestras capacidades (p. 51).

Con la frase "el arte de la educación adaptado a las circunstancias", pareciera que el concepto de adaptación, palabra clave en la terminología de los sistemas de aprendizaje virtual, ya había sido trabajado en el contexto natural por Pestalozzi 
(1746-1827). Necesariamente, el desarrollo de la intuición es la esencia de la educación elemental. "Su influjo en el desarrollo de esta capacidad depende por completo de la presencia de objetos como los que se ofrecen a los sentidos del niño en la realidad de su ambiente" (Pestalozzi, 1996, p. 51).

El niño ordena elementos, adquiere el lenguaje, abstrae y construye conceptos científicos al desarrollar su capacidad intelectual.

Pero en ello ha de estar en relación precisa con la marcha que la naturaleza sigue en la presentación de los objetos de intuición en el niño y, en esta presentación estar unida a la realidad de las condiciones, situaciones y circunstancias del niño (Pestalozzi, 1996, p. 52).

Por su parte, Comenio (1999), respaldándose en las ideas de Cicerón, concluye en su Didáctica Magna, siglo XVI, que las operaciones y procedimientos en el arte de aprender y enseñar deben ser semejantes a la naturaleza.

El orden que se pretende no debemos ni podemos tomarle de otra parte que no sea de la enseñanza de la naturaleza. Sabiamente dice Cicerón: "Nunca erraremos si llevamos a la naturaleza por guía”. Y en otra parte: "Con la naturaleza por maestro no se puede errar en modo alguno” (Comenio, 1999, p. 53).

De ahí se derivan principios pedagógicos, se elaboran manuales escolares y se formulan correctivos para una educación integral y armónica bajo principios de libertad y autonomía.

En el Fundamento IX, capítulo XVII de su obra magna, Comenio (1999, p. 80) ilustra que "la naturaleza no produce sino lo que tiene un uso claro e inmediato". A partir de ejemplos y su correspondiente aplicación en los procesos formativos, desarrolla todos los capítulos:

$\mathrm{Al}$ formar el ave se ve claramente que las alas se destinan para volar, las patas para correr, etc. De igual modo, cuanto nace en el árbol tiene su empleo, hasta la cáscara y la vellosidad que recubren los frutos, etc. Luego, aumentarás la facilidad en el discípulo si le haces ver la aplicación que en la vida común cotidiana tiene todo lo que le enseñes. Esto debe verlo siempre en la gramática, dialéctica, aritmética, geometría, física, etc. De lo contrario, todo cuanto le relates le parecerán monstruos del Mundo Nuevo, y el muchacho que no sea muy diligente creerá que existen en la naturaleza, y cómo existen, en lugar de saberlo por sí mismo. [...] Luego, nada se enseñe sino para su uso inmediato (p. 80).

Según el artículo de Aguirre (2001), en El mundo en imágenes, primera obra didáctica ilustrada de Comenio, el niño aprendía temas anatómicos y fisiológicos, la creación del universo, el sistema planetario, la clasificación de los minerales, las 
plantas y los animales. Ya desde 1520, el alfabeto de letras o "alfabeto simbólico" o "alfabeto vivo", servía para correlacionar la pronunciación de las letras con sonidos onomatopéyicos. Se estableció el valor pedagógico y divertido de los alfabetos visuales para ejercitar la memoria, los cuales consistían en representar las letras iniciales enumerando y ordenando, alfabéticamente, dibujos de animales.

Para Pestalozzi (1996), la visión científica de las cosas parte de un grado de vivificación y significación de los conceptos que se aprenden a partir de los objetos del entorno natural cercano al niño:

Un niño, aunque viva en circunstancias limitadas, conoce, por lo menos, seis mamíferos, otros tantos peces, aves, insectos, anfibios y reptiles; y cuando observa con precisión estos pocos animales, elementalmente desde la primera edad, cuando aprende a conocerlos debidamente en sus partes esenciales y en sus propiedades distintivas, y a expresarse sobre ellos con claridad, tal como se puede y debe conseguir con una enseñanza realmente elemental del lenguaje, incluso en las más ínfimas cabañas, este niño tiene ya el principio de un sólido y natural aprendizaje de la visión científica de los mamíferos, de la ornitología, de la ictiología, etc. (p.62).

Y en cuanto a la física y la química, Pestalozzi continúa enfatizando:

El niño que ha observado con precisión elemental el agua que se le ha ofrecido ante su vista en estado tranquilo, en movimiento en sus variaciones de rocío, lluvia, vapor, hielo, escarcha, etc., y luego en la acción y el influjo de estos diversos estados sobre las demás cosas naturales, habiendo aprendido, al mismo tiempo a expresarse sobre ello con propiedad, tiene ya los principios de la visión artística de las ciencias naturales (p. 63).

\section{Un nuevo hábitat: el ciberespacio}

En el lenguaje de las máquinas, la representación de objetos sigue siendo fundamental para el desarrollo de la inteligencia, pero ahora se diría "inteligencia digital" o "inteligencia artificial”. Así, como el átomo es un prototipo del mundo físico tangible que tiene peso, color y tamaño, en el lenguaje de las máquinas, el bit es un símbolo matemático intangible que representa imágenes, conceptos, lugares, objetos y ambientes. En la súper autopista (la Internet), millones de datos son fragmentados, enrutados y distribuidos mediante bits representados en unidades básicas por ceros y unos. El bit puede desplazarse a la velocidad de la luz en medios radiales, gráficos, televisivos y de papel electrónico. Negroponte (1995) afirma que los sitios web se duplican cada cincuenta días y cada cuatro segundos.

El ciberespacio es un área virtual intangible y digital que pertenece a la nueva sociedad y funciona mediante representaciones numéricas de la realidad. La ciberso- 
ciedad (Silvio, 2000, p. 35) es una nueva red social y la cibercultura es una nueva cultura:

A diferencia del espacio geográfico que conocemos, en el ciberespacio no existe el concepto de "lugar geográfico". Se tiene la impresión de estar en el mismo lugar que personas situadas en distintos lugares geográficos y con los cuales nos estamos comunicando. En el ciberespacio se relacionan individuos, grupos y organizaciones en una compleja red social, a través de computadoras. A esa compleja red social se le ha llamado "cibersociedad".

En el mundo natural, físico y tangible, la interacción se da con objetos reales que el niño puede observar, oler y tocar. "El mundo material, con sus cosas, está ahí, a la vista de todos, con o sin propósito alguno" (Gallego-Badillo, 1998, p. 90), mientras que el proceso comunicativo, desarrollado en el ciberespacio por los seres que lo habitan, tiene lugar en un marco espacial y temporal regulado por patrones de vida en los que la presencia física del cuerpo no es necesaria. El abrazo, el saludo de mano, la mirada cara a cara cambia en estos ambientes, donde cada usuario se identifica con un login, un correo electrónico, una contraseña y una foto. Por ejemplo, en el videojuego Secondlyfe ${ }^{5}$, se construyen personajes en tercera dimensión que visitan diferentes lugares (cafeterías, museos, bibliotecas) y tienen la posibilidad de entrar a nuevos espacios de vida con altos niveles de creatividad e interactividad.

En ese recorrido, del mundo natural al mundo virtual, prolifera una gama de conceptos relacionados con ambientes virtuales, ambientes naturales, ambientes artificiales, ambientes reales, ambientes físicos y ambientes adaptativos, de grandes implicaciones para el currículo escolar. En el universo existen redes físicas y biológicas, redes sociales y telemáticas. Podría afirmarse que toda la vida, y la del mundo físico, químico y biológico, están comprometidas, de alguna manera, con redes. En el ciberespacio, los educadores encuentran contenidos didácticos como libros electrónicos, documentos multimediales, juegos, cartillas, guías, artículos y actividades como tareas, cuestionarios, chats, foros de discusión, cuya finalidad es promover el aprendizaje interactivo. En este contexto, Cartier (1980, citado en Silvio, 2000, p. 31) define la mediática como:

Una disciplina cuyo objeto de estudio serían las condiciones y metodologías a través de las cuales el ser humano podría generar e interpretar contenidos de información de una manera significativa y siguiendo una gramática estructurada, basada en una integración de diferentes medios de expresión, tales como texto, imágenes, sonidos, movimiento, en un solo formato, o sea, lo que más tarde se llamaría comunicación multimedial.

\footnotetext{
${ }^{5}$ Extraído el 23 de julio de 2008 desde http://www.radiocable.com/
} 


\section{Sistemas adaptativos inteligentes}

Un sistema adaptativo es aquel que ajusta su funcionamiento al usuario tomando a éste como unidad esencial en su desempeño. Todas las características y metas de la persona que interactúa con el sistema se ven directamente reflejadas en un cambio de estrategia dentro del funcionamiento del mismo. Estos sistemas realizan evaluaciones, detectan errores, dan sugerencias, ejemplos, simulaciones, recomendaciones al estudiante y constantemente re-planean el modelo de aprendizaje, como lo haría un tutor humano (González, Duque y Ovalle, 2008, p. 199).

Estos autores compilan una serie de características de los sistemas adaptativos en entornos pedagógicos multimedia, soportados en ambientes web, como lo haría un profesor:

- Un sistema adaptativo es inteligente, dinámico, abierto, flexible e interactivo. Su diseño permite identificar las diferencias, las necesidades y los intereses individuales para decidir qué contenidos presentar y adaptar.

- La forma y condiciones de adaptación, previamente determinadas en función de las características del estudiante, son de orden psicológico, pedagógico, de personalidad, estados de ánimo, actitud, motivación, nivel de conocimiento, idioma, edad y otros aspectos que inciden de manera directa o indirecta en el aprendizaje como entorno, clima y aún el estrato social.

- Los sistemas virtuales adaptativos pueden inicializarse (capturar), actualizarse y corregirse hasta que se acomoden o “encajen” en el perfil del estudiante, de acuerdo con información previamente solicitada. Pueden incluir o excluir temas, redefinir el orden de presentación y enlazar actividades.

- Permiten la interacción entre los alumnos con diferentes habilidades, cualidades, ritmos y tiempos. Son aptos para enseñar las diferentes áreas del currículo aplicando principios pedagógicos de diferentes teorías, como solución de problemas, aprendizaje autónomo, aprendizaje colaborativo, entre otras.

- Proporcionan acompañamiento tutorial o autónomo. El nivel de comprensión, se diagnostica evaluando no sólo la respuesta, sino la forma de responder. Dan información de retorno con links (por ejemplo, "no entendí”), además, con ayudas, tips, calculadora, comentarios, llamados de alerta. Mediante un sistema de evaluación constante, muestran registros históricos y estadísticas de las visitas realizadas y de experiencias exitosas o no exitosas. 


\section{Metodología}

Se aplicaron principios, metodología e instrumentos de la investigación evaluativa de materiales de aprendizaje y del estudio de casos. La investigación evaluativa (Weiss, 1985 ) consiste en recoger información para tomar decisiones de mejoramiento acerca de las fallas y los aciertos de programas, planes y proyectos en marcha mediante técnicas cualitativas o cuantitativas. En este caso, se evaluó el ambiente adaptativo multimedia Savmoodle para los estilos de aprendizaje de los niños visuales, auditivos, kinéticos y lectores-escritores, según la clasificación de Fleming (2006), que estaban aprendiendo el tema del medio ambiente natural y medio ambiente social. El estudio de casos (Stake, 1998) es una mirada en profundidad de un evento, un proceso, un programa o un grupo pequeño de personas en un contexto específico y en un periodo de tiempo determinado.

Participó un grupo de 33 estudiantes entre 8 y 10 años de edad, 11 niñas y 22 niños matriculados en el grado tercero de la Normal Superior de Manizales. Según la profesora, los estudiantes presentan buen estado de salud, manifiestan un alto grado de motivación para trabajar frente a los computadores, aunque no todos disponen de ellos en sus casas, y sólo se familiarizan con esta herramienta en las horas programadas para las diferentes áreas en la sala de sistemas recientemente instalada.

En su modelo pedagógico, la institución privilegia la metodología escuela activa, que consiste en la elaboración y desarrollo de guías de aprendizaje mediante los momentos ABCD. Cada momento es esencial y necesario para avanzar en un proceso de aprendizaje que inicia con los saberes previos (A), presentación del tema nuevo o contenidos curriculares (B), aplicación o transferencia de los contenidos aprendidos (C) y evaluación de logros (D). Por sus alcances en el sector rural y en atención a las políticas gubernamentales, últimamente la metodología escuela activa está siendo implementada en la escuela urbana.

El análisis de datos cualitativos se realizó mediante segmentación y categorización, codificación por ciclos de observación. Los datos cuantitativos, mediante tablas de frecuencia, diagramas y gráficos. Se establecieron las características de color, forma y composición de cada uno de los juegos, imágenes, sonidos, animaciones y personajes interactivos.

\section{Resultados}

En correspondencia con la metodología de la investigación evaluativa, los resultados se obtuvieron en tres etapas. La primera consistió en caracterizar la institución y el grupo de participantes, de acuerdo con sus estilos de aprendizaje. La segunda etapa consistió en la elaboración de los guiones en formato plano para su posterior diseño en formato multimedia, ajustable en la plataforma, y, por último, la experimentación con el grupo de niños.

Entre los instrumentos principales y materiales de apoyo que proporcionaron datos relevantes, se utilizaron: registros observacionales, charlas y entrevistas con 
profesores y estudiantes, diarios de campo, filmaciones, grabaciones y fichas para evaluación de expertos en contenido, pedagogía, diseño de imagen fija y móvil y desarrollo multimedia. También se recolectó información mediante descripción de procesos de aprendizaje en cada uno de los momentos ABC de la metodología escuela activa. Los estilos de aprendizaje se caracterizaron mediante el test Vark (por sus siglas en inglés, Visual, Auditive, Read-Writer, Kinestesic) de veinticuatro preguntas propuesto por Fleming (2006).

\section{La plataforma Savmoodle}

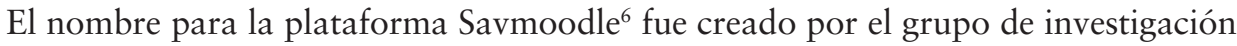
con la participación de expertos en administración de sistemas informáticos de la Universidad Nacional de Colombia, Sede Manizales. Se trata de un sistema administrador de contenidos para cursos virtuales que se adapta a estilos, ritmos y características personales de los estudiantes. Las tres primeras letras ("sav") de la palabra corresponden a las iniciales del sistema adaptativo virtual. El "sav" se fusiona con la plataforma "moodle", a la cual se puede acceder con su correspondiente dirección en el sitio web http://savmoodle.freehostia.com/savmoodle.

Para el caso de este proyecto de investigación, Savmoodle permite acceder a un ambiente virtual adaptado a los estilos de aprendizaje, de estudiantes de educación básica que se encuentran aprendiendo el tema del medio ambiente natural, y el medio ambiente social. Savmoodle es, entonces, un ambiente adaptativo desarrollado para la plataforma Moodle (moodle.org), que es un sistema administrador de contenidos con aplicación web en el que se mezclan diversas tecnologías, entre las que se destacan PHP, HTML, JavaScript y Flash.

Moodle ${ }^{7}$ es una plataforma conocida como "Entorno de aprendizaje modular y dinámico orientado a objetos”. Es de libre distribución y ayuda a los educadores a crear comunidades de aprendizaje en línea. Por eso fue posible para el grupo de investigación utilizar Moodle sin mayores restricciones de mercado. La plataforma ofrece una serie flexible de actividades para ambientes virtuales: texto, envío de mensajes a foros, entradas en el diario, herramientas multimedia, cuestionarios, materiales didácticos, consultas, encuestas y tareas.

Cuando el estudiante ingresa a las actividades adaptativas de Savmoodle, la plataforma carga su historial académico buscando el último material educativo visitado. Si es la primera vez que el estudiante accede, visualiza los materiales del momento A de la guía, correspondiente a su estilo de aprendizaje.

\footnotetext{
${ }^{6}$ Material elaborado por los grupos Innovación Educativa y Semillero Edumática de la Universidad de Caldas y el grupo Ambientes Inteligentes Adaptativos, Gaia, de la Universidad Nacional de Colombia, Sede Manizales, en el desarrollo de la investigación "Diseño, aplicación y validación de un ambiente informático adaptativo para el aprendizaje en educación básica". Manizales, 2007-2008.

${ }^{7}$ Extraído el 13 de octubre de 2008 desde http://blog.pucp.edu.pe/item/26522.
} 
Cuando el estudiante termina las actividades, pulsa el botón "continuar". Inmediatamente, el sistema almacena los resultados, actualiza su historia académica y carga el material del momento siguiente. Esta misma secuencia de pasos se sigue en todos los momentos ABC de la guía. El enlace "mostrar los resultados", ubicado en la esquina superior izquierda, muestra al estudiante su historial académico, fecha y hora de acceso, materiales visitados, aciertos, errores, tiempo empleado, puntaje obtenido, número de intentos y otras informaciones adicionales que permiten hacer seguimiento de las acciones sobre la plataforma.

\section{Guiones didácticos para Savmoodle}

En un filme, un programa radial o televisivo, se elabora el contenido de un texto con todos los detalles e indicaciones necesarios para que los actores puedan representar la obra con alto grado de fidelidad durante la puesta en escena. Con esta misma dosis de creatividad y secuencia, se elaboró el guión didáctico multimedia para esta investigación, en este caso, con fines de enseñanza y aprendizaje.

Primero se diseña un formato plano que sirve como guía, para posteriormente desarrollar las actividades interactivas en la plataforma virtual. Se elaboraron dieciséis guiones distintos (cuatro para cada estilo de aprendizaje), con el fin de obtener el mismo logro: diferenciar y relacionar el medio ambiente natural y medio ambiente social, pero por rutas diferentes, teniendo en cuenta el test Vark. El tema curricular se tomó de una serie de textos validados en un proyecto anterior (Velásquez, Mejía y Rojas, 2003), inscrito en la línea de currículo del grupo de investigación.

Cada uno de los guiones consta de los tres momentos, A, B y C, propuestos por la metodología escuela activa para básica primaria, de acuerdo con los lineamientos del Ministerio de Educación Nacional. El momento A se refiere a las actividades básicas o vivencias. Se realiza para explorar en el estudiante sus conocimientos previos, actitudes y experiencias, antes de introducir el tema nuevo. Las actividades deben ser lúdicas, despertar interés y expectativas y permitir la acomodación y asimilación del nuevo tema.

El momento B se refiere a la fundamentación temática. Se proporciona el contenido teórico o información nueva que va a aprender el estudiante y su relación con sus propias ideas y experiencias del momento anterior. También permite complementar sus propias ideas y experiencias mediante lecturas, documentos, trabajos de campo, anexos, entre otros. El momento $\mathrm{C}$ se refiere a las actividades de aplicación y evaluación del conocimiento aprendido.

En el diseño y estructura de cada actividad constitutiva del guión, se desarrollaron los siguientes pasos: primero, selección de contenidos y actividades para ser llevados a la plataforma. Luego, identificación y caracterización de personajes, combinación de contenidos e interacciones. También se expuso, paso a paso, la narración de lo que debían decir o hacer los personajes seleccionados y cómo debe 
estar dispuesto el escenario. Por último, se lleva a cabo la descripción y secuencia de las escenas.

Los colores en los textos fueron ayudas muy importantes a la hora de diseñar el guión en forma física, ya que permitían: 1) diferenciar la descripción del personaje en cada actividad; 2) mostrar lo que se quiere en la plataforma virtual; 3) narrar lo que dirán los personajes acerca del contenido del texto y las instrucciones a seguir; 4) diferenciar con colores el sentido de los textos y las escenas. En negro se escribía la descripción de las actividades y sugerencias a tener en cuenta a la hora de llevar los guiones a la plataforma. En color rojo se marca lo que los personajes debían decir. En todas las actividades se tuvieron en cuenta las características de los niños, de acuerdo con las categorías visuales, auditivas, escritoras-lectoras y kinéticas de Fleming (2006).

Los estudiantes de estilo visual aprenden y recuerdan mejor con imágenes, cuadros, diagramas, círculos, gráficas, ideogramas, flechas y láminas. Les gusta un ambiente ordenado para su trabajo. En sus primeros años de vida, les gusta ver fotografías, dibujos y cuentos ilustrados, ojalá con movimiento.

Los estudiantes de estilo auditivo atienden muy bien a las exposiciones orales de sus profesores o compañeros y las recuerdan con facilidad. Las conferencias, las discusiones grupales, programas radiales y canciones son excelentes ayudas didácticas, así como la voz, el oído y seguir instrucciones. Puesto que su capacidad de escucha les permite desarrollar la habilidad de expresión verbal, no necesitan tomar muchos apuntes.

Los estudiantes de estilo kinestésico o kinético obtienen éxito en el aprendizaje y recuerdan lo que aprenden mediante actividades que involucren manipulación de materiales y experiencias prácticas. "Aprender haciendo" es el principio pedagógico que los identifica. Se les facilita actuar o hacer cosas, realizar proyectos y mantenerse ocupados, ya sea en simulaciones o ejecuciones reales. Representan físicamente lo que dicen y son excelentes actores en escena.

Los estudiantes de estilo lector-escritor tienen mayor desarrollo en las habilidades de lectura y escritura, vocalizan la lectura, repiten las ideas al momento de recordarlas y se les dificulta permanecer sentados y en silencio por largo tiempo. También se diferencian de sus compañeros porque atienden cuidadosamente las instrucciones orales o escritas del profesor, toman apuntes, los leen varias veces y los corrigen, hacen resúmenes con sus propias palabras, inventan cuentos a partir de imágenes y son muy organizados en el estudio.

La plataforma arrojó los siguientes resultados: del grupo de 33 estudiantes, 13 son lectores, 9 son visuales, 7 son auditivos y 4 son kinéticos.

Generalmente, niños y niñas no sabían que tenían una manera especial de aprender. Algunos decían que aprendían muy despacio y que, en cambio, tenían compañeros que aprendían mucho más rápido que ellos, pero nunca relacionaron este hecho con la teoría de los estilos de aprendizaje. 
De acuerdo con las observaciones, los resultados fueron coherentes con respecto al estilo de aprendizaje. Las actividades realizadas fueron de agrado para cada uno de los estudiantes y las desarrollaron en el tiempo previsto, entre quince y veinte minutos, según los registros de la plataforma. Los aciertos en el momento $\mathrm{C}$ se registraron con pocos intentos de repetición y pocos desaciertos.

\section{Personajes para la plataforma}

Se crearon personajes con características muy especiales. Los modelos se tomaron de los dibujos más frecuentes que hacen los niños en sus cuadernos. Ellos fueron: Guacamaya, un niño llamado Colombianito y una niña llamada Colombianita.

Guacamaya es la encargada de dar las instrucciones para desarrollar la actividad. Es de color rojo y siempre manifiesta un aleteo para dar a entender que tiene algo que contar. Guacamaya está ubicada en el extremo izquierdo inferior de la plataforma y explica los guiones relacionados con el medio ambiente natural. Por ejemplo, saliendo por el agujero de la letra A, Guacamaya dice: "Hola amiguitoamiguita, hoy aprenderemos juntos acerca del medio ambiente. Haz clic sobre mi pico, tengo algo que contarte, ¿sabías que el medio ambiente es el espacio en el que interactúan elementos naturales, sociales y culturales?”.

Colombianito y Colombianita representan el medio ambiente social y siempre están ubicados en el extremo inferior derecho de la plataforma. Por ejemplo: "Recuerda que tanto los elementos naturales como los elementos sociales hacen parte del medio ambiente, no están separados y se encuentran en constante interacción”.

\section{Guiones didácticos en la plataforma}

A continuación se muestran los materiales multimedia del ambiente adaptativo instalados en la plataforma para cada uno de los estilos de aprendizaje, teniendo en cuenta los momentos $\mathrm{ABCD}$ de la guía con metodología escuela activa, según el modelo pedagógico de la institución objeto de estudio.

\section{Para el estilo de aprendizaje visual}

Para iniciar el momento A de la guía, se presenta la ruleta dividida en diez partes, cinco son de color azul y cinco de color amarillo. Al lado de la ruleta hay una lista de palabras: agua, escuela, bosque, cultura, tradiciones, suelo, familia, plantas, fauna y amigos. En la parte inferior izquierda aparece Guacamaya diciendo: "Ubica en las áreas azules del círculo elementos de la naturaleza y en las áreas amarillas del círculo, elementos de la sociedad." 


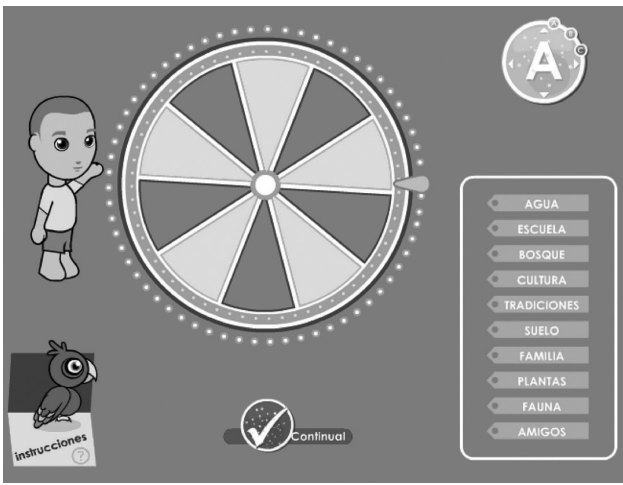

Fuente: http://savmoodle.freehostia.com/savmodle

Se da clic en la mano del niño o niña que aparece al lado izquierdo de la ruleta para que la haga girar. Al lado derecho de la ruleta hay una flecha de color verde indicando en qué color se detiene cuando deje de girar. Esta posibilidad de movimiento no la ofrecen las cartillas o módulos planos impresos que manejan las escuelas. Cuando la ruleta se detiene, el niño arrastra con el mouse una palabra de la lista que está a la derecha de la ruleta. Si se detiene en el color amarillo, el niño escoge de la lista una palabra que pertenece a la sociedad o a la ciudad. Si la ruleta se detiene en el color azul, la palabra que debe arrastrar hacia ella pertenece a la naturaleza. Cuando el niño haya ubicado todas las palabras, hace clic en "continuar", ubicado en la parte inferior central de la pantalla. Inmediatamente, el sistema le reporta cuántas palabras ubicó bien y cuántas no. Hay un número de aciertos que permite al personaje de la animación convertirse en superhéroe. Luego pasa a la siguiente actividad.

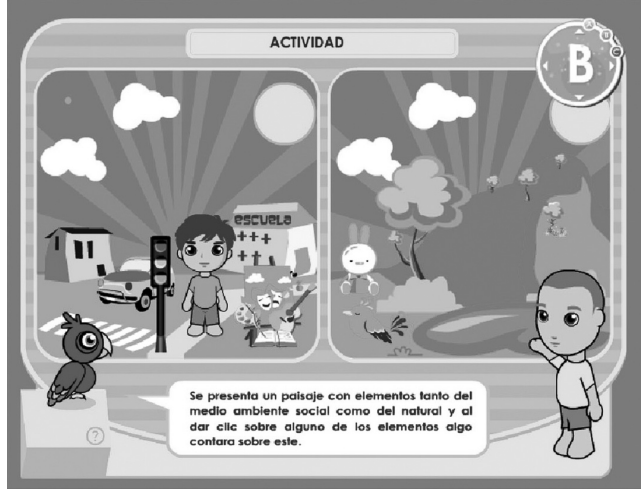


En el momento B, se encuentran dos paisajes: uno representa el medio ambiente natural y el otro, el medio ambiente social. Guacamaya dice que cuando el niño dé clic sobre alguno de los elementos que componen cada paisaje, le mostrará una información importante. A medida que el niño va dando clic sobre los objetos dibujados, va conformando el concepto de medio ambiente, tanto natural como social, y los elementos que lo componen. Los paisajes, para el medio ambiente natural, contienen elementos como ave, árbol, lago, conejo, montaña. Al hacer clic sobre ellos se conecta con una pequeña descripción de cada uno. En el medio ambiente social, los elementos distintivos son: escuela, casa, hombre, la cultura, las normas (bandera, cebra o semáforo) y el carro. Al hacer clic sobre ellos se obtiene la información o contenido a aprender. Al finalizar, el estudiante puede leerlos nuevamente. Cuando crea que ya los relaciona y los identifica, está preparado para pasar a la siguiente actividad, C.

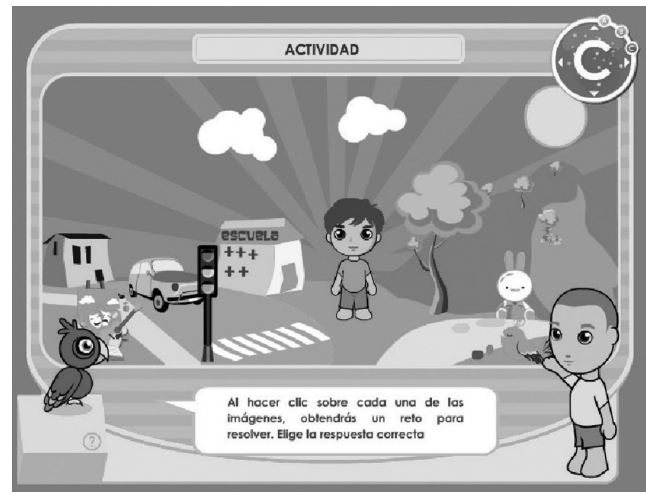

Fuente: http://savmoodle.freehostia.com/savmodle

La actividad C evalúa el concepto de medio ambiente trabajado en las actividades anteriores. Guacamaya dice: "al hacer clic sobre las imágenes obtendrás un reto para resolver. Elige la respuesta correcta”. En esta actividad, al hacer clic sobre cualquiera de las imágenes, aparece el test con cuatro posibilidades de respuesta, de las cuales sólo una es la verdadera. Al finalizar, el niño da clic en la opción "continuar” y aparece el número de aciertos o errores obtenidos. Si el estudiante aprueba la actividad, se convierte en un superhéroe y la plataforma le muestra una especie de fiesta por haberlo conseguido.

\section{Para el estilo de aprendizaje auditivo}

En el momento A, el estudiante observa imágenes y al mismo tiempo escucha un video tomado de YouTube (http://www.youtube.com/watch?v=Ilv2AvJiW_c\&featu re=related) para identificar elementos del medio ambiente natural y social. Guacamaya dice: "en el siguiente video, encontrarás elementos tanto del medio ambiente 
natural como del medio ambiente social. Identifícalos y presta atención a la información".
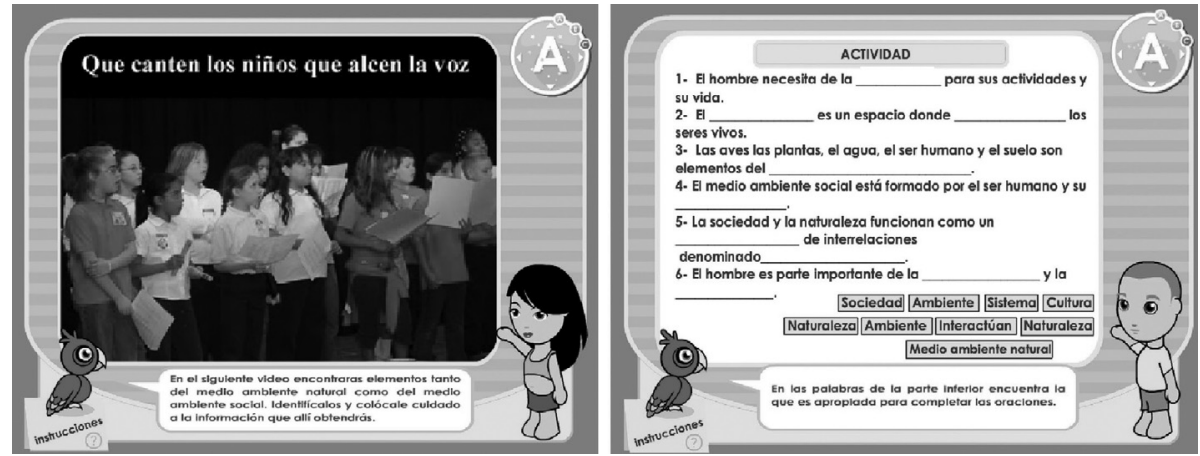

Fuente: http://savmoodle.freehostia.com/savmodle

En otra actividad, se presentan seis frases a las cuales les falta una o dos palabras. En la parte inferior izquierda, se encuentra una lista de elementos como sociedad, sistema, cultura, naturaleza, ambiente, interactuar, medio ambiente natural. Al pasar el mouse sobre ellos, se escuchan voces. El estudiante debe arrastrar las palabras faltantes hacia la frase para darle sentido completo a la oración. Por ejemplo, en la frase numero uno dice: "el hombre necesita de la para sus actividades y su vida". Las posibles respuestas estarían entre sociedad, cultura y naturaleza. La respuesta correcta es "naturaleza". Al completar todas las oraciones, da clic en el botón "continuar" y el sistema reporta los errores y los aciertos.

En el momento B, se encuentra una canción alusiva al medio ambiente. Una de las cinco estrofas ${ }^{8}$ es la siguiente: "El sol a todos calienta. El agua nos da la vida. Plantas y animales nos alimentan. Y el hombre todo lo cuida". Guacamaya da la siguiente instrucción: "escucha la canción y escribe lo que entiendes por medio ambiente, los elementos que lo componen y el mensaje que te dejó. Puedes detener o continuar la canción haciendo clic sobre el botón que aparece al lado izquierdo de ésta".

Otra actividad consiste en que el niño debe dar clic en el ícono "escuchar explicación”. Guacamaya explica lo que es el medio ambiente natural y el medio ambiente social. En la pantalla van apareciendo los elementos constitutivos. Guacamaya da la siguiente instrucción: "escucha atentamente la explicación sobre medio ambiente natural y medio ambiente social.”

En el momento C, se escuchan cuatro frases incompletas al pasar el mouse; cada una con cinco o seis posibilidades de respuesta. Una de las frases dice: "El

\footnotetext{
${ }^{8}$ Tomado del portafolio de investigación de la estudiante de Maestría en Educación Gloria Marcela Flórez Espinosa, quien participó como auxiliar de investigación.
} 
es el

donde interactúan elementos, sociales, culturales y naturales". Las opciones de respuesta son, mundo, ecosistema, medio ambiente, espacio, hombre. De éstas, el niño debe seleccionar dos que correspondan, en su orden, para darle sentido completo a la oración. En este caso son, respectivamente, medio, ambiente y espacio.

\section{Para el estilo de aprendizaje lector-escritor}

Para el momento A, se presenta un texto escrito con la posibilidad de resaltar palabras mientras el estudiante lo va leyendo en la pantalla. Con el mouse, se arrastra un marcador rojo o verde simulado, correspondiente a los elementos del medio que se desea resaltar. Por ejemplo, las palabras "cultura, normas, religión" deben subrayarse con el marcador rojo, porque pertenecen al medio ambiente social. Las palabras "agua, plantas, animales" deben ir en verde, porque pertenecen al medio ambiente natural.

El momento B presenta un cuento que debe ser leído por el estudiante. Guacamaya dice: "Bienvenido al momento $B$ de nuestra aventura. Realiza cuidadosamente la lectura y presta mucha atención a lo que en ella te dicen. Necesitarás esta información para el momento C".

La actividad C consiste en encontrar la idea central de cada uno de los enunciados que van apareciendo al dar clic en el botón "siguiente pregunta". Cada enunciado tiene cuatro posibilidades de respuesta, de las cuales sólo una es correcta. Al finalizar, el niño da clic en "continuar" y el sistema reporta automáticamente los aciertos y los errores. Si el niño tiene un número elevado de aciertos, se convierte en superhéroe. Si no lo logra, se escucha un abucheo y el personaje sale imitando un gesto de tristeza; el niño debe hacer nuevamente el recorrido. Quienes acierten todos los ejercicios, pasarán a un nuevo logro de aprendizaje.

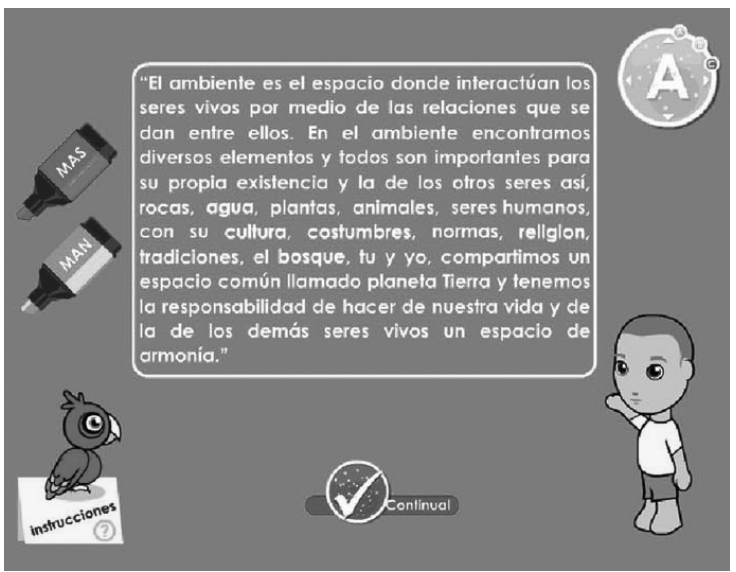



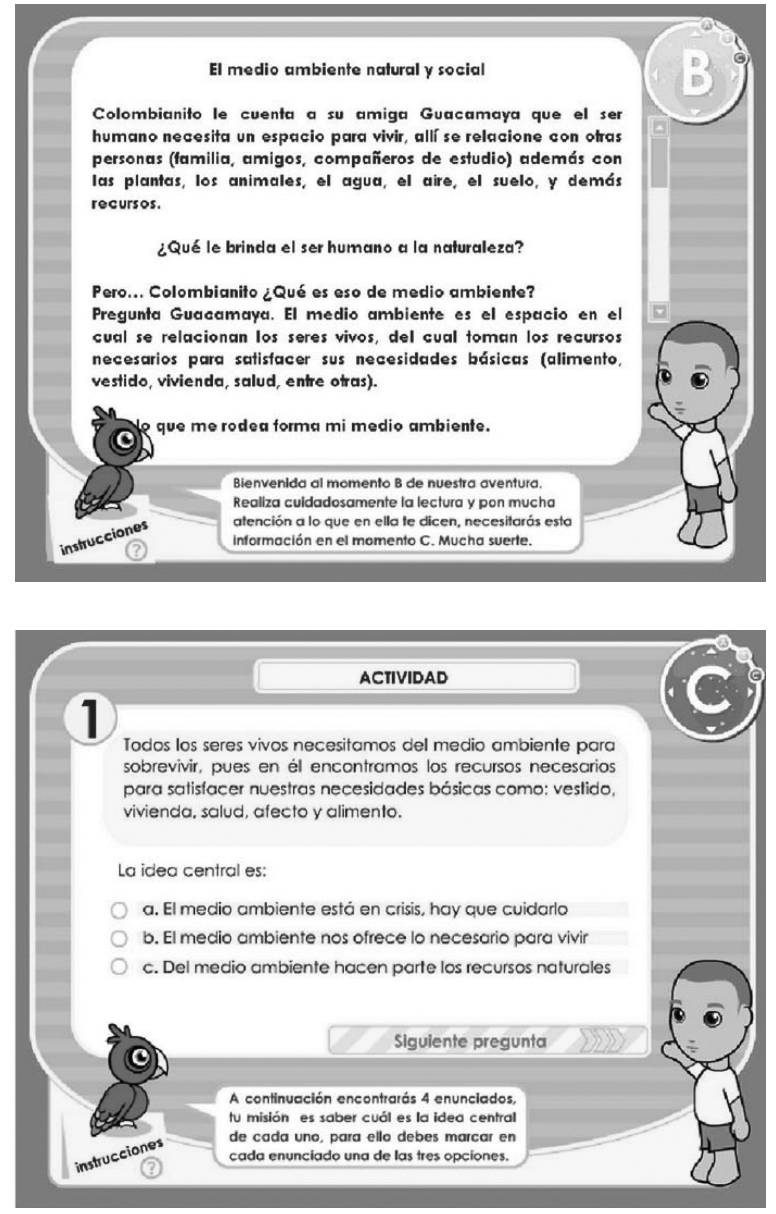

Fuente: http://savmoodle.freehostia.com/savmodle

\section{Para el estilo de aprendizaje kinético}

En el momento A, se arman dos rompecabezas, uno del medio ambiente natural y otro del medio ambiente social. Hay una lista de fichas con el nombre de elementos de ambos medios; deben arrastrarse y encajarse en el lugar al que pertenecen. Sale Guacamaya dando instrucciones: "Arma el rompecabezas con las fichas de los elementos que corresponden a la sociedad. Para esto cuentas con tres minutos. Arma el rompecabezas con las fichas de los elementos que corresponden a la naturaleza. Para esto cuentas con tres minutos”. 


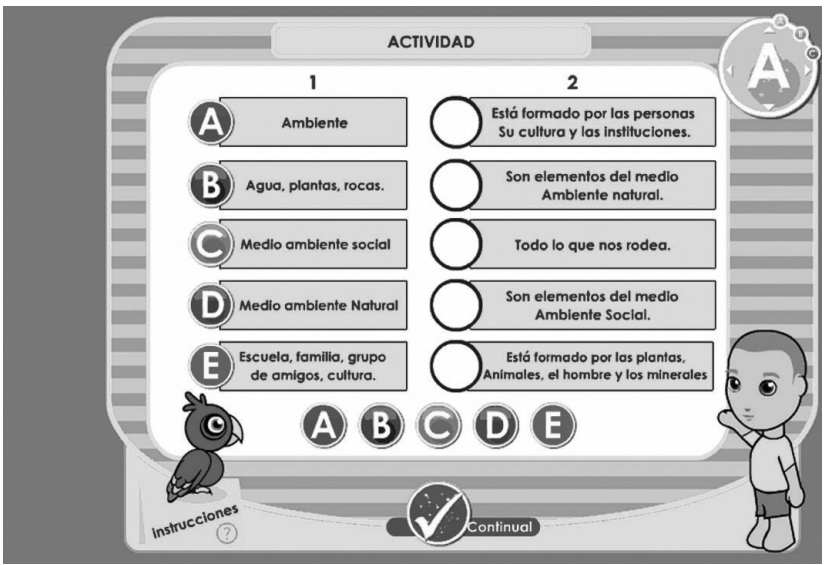

Fuente: http://savmoodle.freehostia.com/savmodle

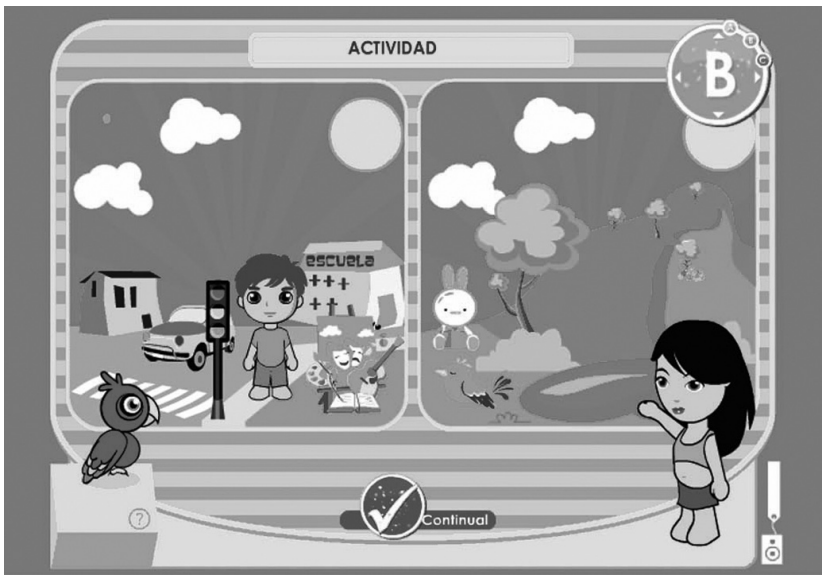

Fuente: http://savmoodle.freehostia.com/savmodle

En el momento B, Guacamaya presenta un video con imágenes del medio ambiente social y del medio ambiente natural. En el momento C, se muestra la estructura de un mapa conceptual con algunos conectores, y la siguiente lista de palabras: espacio, seres vivos y no vivos, medio ambiente social, agua, animales, plantas, sistema, instituciones, cultura, sociedad, medio ambiente natural. El estudiante completa el mapa arrastrando el cursor hasta los cuadros correspondientes. El ícono "verificar", junto al mapa, muestra el número de errores y aciertos. 


\section{Reflexión ambiental}

Colciencias, y las diferentes instituciones financiadoras de investigaciones en todas las áreas del solicitan últimamente, como requisito fundamental de aprobación, una reflexión sobre los efectos positivos o negativos de los resultados sobre el medio ambiente. Aunque el trabajo de los niños con Savmoodle, frente a la plataforma, no originó efectos negativos, por el contrario, fueron placenteros y estimulantes desde el escenario educativo, el grupo ejecutor de este proyecto reflexionó acerca de algunos puntos importantes, asumiendo que el medio ambiente puede referirse al entorno que afecta y condiciona la calidad de vida de los organismos, la sociedad, la cultura y la naturaleza en general. Es decir, medio ambiente es todo aquello que nos rodea y forma parte de nuestro diario vivir.

El concepto de tecnologías limpias, que últimamente se ha posicionado en la industria, el comercio y la empresa, es una propuesta amigable con el ambiente, porque su propósito es reducir la contaminación y aumentar la calidad de los recursos sin causar daño a la naturaleza ni a las especies que la habitan. El mundo virtual, al ser intangible y digital, pertenecería a la categoría de tecnologías limpias, por cuanto es evidente que estas herramientas tecnológicas reemplazan el papel, lo cual incide en la preservación y conservación de los bosques.

Las Tecnologías de la Información y Comunicación en la educación, la cultura, la economía y el desarrollo social han sido un factor clave en los diferentes países que las crean y utilizan. No obstante, es importante reflexionar sobre otros efectos que pueden incidir de manera positiva o negativa en la salud y el bienestar de las personas y la naturaleza. ¿Hasta qué punto la notable incidencia de las tecnologías, en el comportamiento de las nuevas generaciones digitales, ha llevado a debilitar la identidad cultural por adoptar una cultura artificial? ¿Hasta qué punto la interacción con personajes ficticios en foros, chats y juegos, es mejor que la interacción con los objetos reales del mundo natural?

Según numerosos estudios en el tema' ${ }^{9}$ el uso exagerado de computadores ha ocasionado diferentes problemas de salud. La población infantil y juvenil ha dejado de desarrollar sus cuerpos mediante juegos al aire libre, por permanecer más de doce horas diarias frente a un equipo. Dictámenes médicos ${ }^{10}$ han diagnosticado problemas como: 1) nuevas formas de dependencia adictiva con sus correspondientes efectos psicológicos. 2) Sobreesfuerzo y enrojecimiento de los ojos atribuible a la pantalla. 3) Tecnoestrés, malestar corporal, dolor en el cuello, brazos, espalda y ojos borrosos. 4) Adormecimiento y angustia por el incalculable volumen de in-

\footnotetext{
${ }^{9}$ Extraído el 31 de enero de 2009 desde http://www.healthsystem.virginia.edu/UVAHealth/adult_eye_ sp/vdts.cfm

${ }^{10}$ Extraído el 15 de diciembre de 2008 desde http://www.usergioarboleda.edu.co/grupointernet/tecnoestres.htm
} 
formación. 5) Postura ergonómica inadecuada. 6) Tendinitis por uso prolongado del teclado. 7) Obesidad debida al sedentarismo. 8) Cambio de hábitos culturales, alimentarios, recreacionales y de estudio frente a las nuevas formas de acceder a la información.

\section{Conclusiones}

Con Savmoodle se tiene como resultado un proceso de enseñanza más atractivo para el estudiante y mejor adaptado a sus estilos de aprendizaje. La plataforma ofrece la disponibilidad para soportar contenidos multimedia, evaluar al estudiante, identificar sus perfiles, ubicarlo y guiarlo durante el proceso de aprendizaje.

La forma de promover el aprendizaje relacionado con el tema del medio ambiente natural y del medio ambiente social, correspondiente al currículo de básica primaria, deja de ser mecánica e impuesta por el profesor, porque los estudiantes seleccionan los contenidos de su interés, al acceder a la plataforma Savmoodle. Es posible presentar materiales adaptados a sus estilos de aprendizaje, visual, auditivo, kinético, lector-escritor, siendo este último el estilo que caracterizó al mayor número de estudiantes del grupo participante, con un $40 \%$. El $27 \%, 21 \%$ y $12 \%$ restante fue obtenido por los otros tres estilos, respectivamente.

Savmoodle permite relacionar información nueva con información previa, evidenciando así un principio de la pedagogía activa, modelo elegido por la institución donde se desarrolló el ambiente adaptativo. Cada niño, a su propio ritmo, desarrolla todas las actividades y obtiene los logros propuestos en la guía de aprendizaje, descubriendo procesos, a partir de los conocimientos que ya posee, sobre su interacción con el medio ambiente natural y social que lo rodea.

Son tres los factores determinantes a la hora de acceder al sistema adaptativo: el diseño y la adaptabilidad, el contexto de aprendizaje y el papel del estudiante. Las teorías sobre estilos de aprendizaje ofrecen elementos válidos para comprender la manera en que el estudiante aprende y ayudan a los investigadores a determinar las condiciones propicias para utilizar el ambiente adaptativo Savmoodle, de manera que genere significatividad, adaptabilidad e interactividad. Se observa que el estudiante no aprende de manera mecánica, sino que va relacionando sus saberes previos con la nueva información y su inmediata aplicación.

El ambiente adaptativo Savmoodle, creado durante el proyecto, es atractivo para los estudiantes porque favorece el aprendizaje mediante el texto animado, imagen en movimiento, color, sonido, video, animaciones, representación de objetos y diálogo entre personajes que interactúan con el tema del medio ambiente, haciendo uso de su creatividad, imaginación y actitud positiva hacia los computadores. Los materiales didácticos interactivos, con estas características, ofrecen temáticas y problemáticas para el desarrollo de la investigación educativa, pedagógica y curricular, propuesta por las líneas de investigación de los grupos gestores del proyecto. 
Esta investigación deja al currículo escolar aportes teóricos, metodológicos y pedagógicos adaptados al nivel básico en escuela activa. Así como se evidenció en el área de educación ambiental, se podrán incorporar experiencias similares en las diferentes áreas aprendibles y enseñables del currículo escolar.

El referente pedagógico de los materiales didácticos, adaptados a los estilos de aprendizaje de los escolares en ambientes virtuales, como se constató con Savmoodle, abre nuevos campos de acción, planteando interrogantes importantes, aún no resueltos, que incrementan las agendas de los educadores frente al advenimiento imparable de las nuevas tecnologías. Por ejemplo, ¿los modelos pedagógicos están atendiendo a las características de las nuevas generaciones de niños y jóvenes cada vez más digitales? ¿Qué nuevas herramientas tecnológicas pueden ser utilizadas para que la enseñanza responda a los estilos de aprendizaje, a las necesidades del contexto social, tecnológico, económico, político y cultural? ¿De qué manera la escuela y la universidad están comprendiendo, creando, transformando y protegiendo los ambientes naturales y virtuales que forman parte de los nuevos hábitos de vida en el espacio geográfico y en el ciberespacio? 


\section{Referencias bibliográficas}

Aguirre, M. (2001). Enseñar con textos e imágenes. Una de las aportaciones de Juan Amós Comenio. Revista Electrónica de Investigación Educativa, 3(1). Obtenido el 12 de abril de 2007, desde http://redie. uabc.mx/vol3no1/contenido-lora.html

Cartier, M. (1980). La médiatique. Montréal, Canadá: Éditions du Laboratoire de TélématiqueUniversité du Québec à Montréal.

Comenio, J. (1999). Didáctica Magna. México: Porrúa.

Dewey, J. (1960). Las escuelas de mañana. Buenos Aires: Losada.

Fleming, N. (2006). Teaching and learning styles: Vark strategies. Christchurch, Nueva Zelanda: Digital Print and Copy Centre.

Freinet, C. (1970). Los métodos naturales. Barcelona: Fontanela.

Gallego, D. J. (2004). Diagnosticar los estilos de aprendizaje. Obtenido el 4 septiembre de 2007, en http://www. ciea.udec.cl/trabajos/Domingo\%20Gallego.pdf.

Gallego-Badillo, R. (1998). Discurso constructivista sobre las tecnologías. Una mirada epistemológica. Bogotá: Magisterio.

Galvis, A. (1997). Micromundos lúdicos interactivos: aspectos críticos en su diseño y desarrollo. Informática
Educativa, 2(10), 191-204. Obtenido el 18 de noviembre de 2008, desde http:// www.colombiaaprende.edu.co/html/ mediateca/1607/articles-112594_archivo.pdf.

Gardner, H. (2005). Las cinco mentes del futuro. Barcelona: Paidós.

González, H., Duque, N. y Ovalle, D. (2008). Modelo de estudiante para sistemas adaptativos de educación virtual. Revista Avances en Sistemas e Informática, 1, 199-206.

Ministerio de Educación Nacional. (s. f.). Escuela Nueva en Colombia. Obtenido el 13 de julio de 2008, desde http://www.colombiaaprende.edu.co/ html/home/

Negroponte, N. (1995). Being Digital. New York: Knopf.

Pestalozzi, J. (1996). Canto del cisne. México: Porrúa.

Piaget, J. (1973). El juicio y el razonamiento en el niño. Estudios sobre la lógica del niño. Buenos Aires: Guadalupe.

Rogers, C. \& Freiberg, J. (1986). Libertad y creatividad en la educación en la década de los ochenta. Obtenido el 10 de agosto de 2009, desde http:// www.agapea.com/libros/

Silvio, J. (2000). La virtualización de la universidad. Caracas: Instituto 
Internacional de Educación Superior en América Latina y el Caribe, IesalcUnesco.

STAKE, R. (1998). Investigación con estudio de casos. Madrid: Morata.
Velásquez, J., Mejía, D. \& Rojas, E. (2003). Texto didáctico de educación ambiental soñando un planeta. Grado quinto. Manizales: Manigraf.

WeIss, C. (1985). Investigación evaluativa. México: Trillas. 